\title{
The Market Valuation Of Pre-Registration For Firms In The Online Gaming Industry
}

\author{
Jihong Min, Myongji University, South Korea \\ Yun Kyung Oh, Dongduk Women's University, South Korea
}

\begin{abstract}
Under the uncertainty of market conditions, top management and shareholders keep seeking evidence for whether a new product development project truly improves firm value. In an effort to find the evidence, this study examines the effect of firm's innovative outcome on stock market performance. Specifically, we conduct an event study to test whether stock market reacts to preregistration marketing campaign in online game. In the business practice, the pre-registration is often considered as an important event right before the commercialization of a new game launch. In our empirical analysis on the pre-registration events and daily stock returns of game companies in 2010-2014, we find that stock market responds to the pre-registration event of a new online game positively, with the abnormal returns up to $1.49 \%$. In addition, the stock market rewards the pre-registration events of small firms more than that of large firms. Overall results suggest that stock investors take into account the pre-registration event as economically valuable information and perceive the uncertainty of the innovation process resolved.
\end{abstract}

Keywords: Marketing-Finance Interface; Marketing Campaign; Pre-registration; Online Game; Event Study

\section{INTRODUCTION}

ame industry is a fast-growing business and explodes with rapid penetration of the Internet and mobile devices. Online gaming has become one of the most profitable businesses with a great growth potential. For example, the global market of the online game is expected to reach $\$ 35$ billion by 2017 (Forbes 2012). In the rapidly growing market, product innovation through developing new products is vital to a firm's survival and success, as Cooper (2005) indicated. Moreover, in the turbulent market such as the online game industry, the innovation is especially critical to the success (Kim 2014).

Previous studies on the new product development (NPD) process and market valuation show the mixed results depending on the phases of NPD project. The NPD process covers from the initiation stage to the commercialization stage. At the initiation stage, stock market reacts negatively on average due to the risk of the project. On the contrary, at the commercialization stage, stock market reacts positively as the uncertainty about the project is resolved and the product is ready to generate new cash flows. In this study, we focus on the stock market's reaction to pre-registration event, which is a unique phase right before commercialization in the game industry. Preregistration is a widely used marketing campaign to promote new online game. While media advertising requires relatively expensive cost, the marketing campaign of pre-registration enables the game publishers to recruit users efficiently even with less marketing cost. Additionally, pre-registration campaigns not only enhance recruiting consumers, but also provide economically meaningful information to the stock market.

This study aims to investigate the economic value of the pre-registration campaign as an outcome of the NPD process in the online game. To do so, we empirically test whether the abnormal stock return related to the event exists. As an empirical analysis, we utilize news articles related to the pre-registration campaigns of Korean online game companies during 2010 to 2014. Consistent with the prior studies on the NPD process, we adopt the event study methodology by assuming that the abnormal stock market returns is the consequence of an unexpected event of the firm's NPD outcomes (e.g., Chaney et al. 1991; Fang et al. 2015; Sood and Tellis 2009). Our main empirical findings from the event study include that the pre-registration event generates significantly positive 
abnormal returns. Our additional finding also suggests that the small firms gain more returns from pre-registration event. These results highlight the impacts of marketing actions on stock investors' responses. That is, at the preregistration event, investors anticipate increasing future cash flows and decreasing risks related to the NPD project (Srinivasan et al. 2009; Srivastava et al. 1998).

This study contributes to the existing literature in several ways. First, although prior research on the game industry has examined consumers' adoption behavior of new product (Hsu and $\mathrm{Lu}$ 2007; Park and Chung 2011; Jung et al. 2014; Yee 2005), to the best of our knowledge, this is among the first to examine the economic value of NPD outcome in terms of pre-registration in game industry. Second, this study contributes to the marketing-finance interface literature, by providing new insights on the financial value of NPD process (Chaney et al. 1991; Kelm et al. 1995; Sood and Tellis 2009; Srinivasan et al. 2009) in the context of game industry. Third, this study also verifies whether the moderating role of the structural variable (i.e., firm size) in the stock market reactions to the new product announcement (Kelm et al. 1995; Rubera and Kirca 2012; Sood and Tellis 2009) is also applicable to the pre-registration event.

The rest of the paper is written as follows. We review the related literature and build hypotheses. Then we explain our data and econometric model for event study analysis, and discuss the results. Lastly, we conclude with summary, limitations and future research.

\section{THEORY AND HYPOTHESES}

\section{Pre-registration in Online Game}

Global game industry revenue is expected to reach $\$ 82$ billion in 2017 (Forbes 2012). The revenue comes from game software and gaming platforms including consoles, portable hardware, Internet browser, and mobile devices. Among them, mobile game is the most lucrative sector and has experienced a dramatic increase of $42 \%$ from 2013 to 2014 (gameindustry.biz 2014).

The recently developed business model in game industry is "freemium", which is combing two words "free" and "premium" (Moreira et al. 2013; Oh and Min 2015). With a freemium game, the users purchase a game for free, but they need to pay for later, which is called "in-app purchase", to enhance gaming experience with advanced features, functionalities or virtual goods. Freemium model based on Android and iOS platforms is pervasive due to the low distributional cost, with contributing to the success of mobile game. According to Moreira et al. (2013), approximately $98 \%$ of most profitable games on both platforms are the freemium games, and mobile game users are willing to pay $\$ 14$ per an in-app purchase transaction on average.

As a few portions of total users generate the in-app purchase transactions, acquiring a large base of new users is critical for the success of freemium game. To capture the larger user base, pre-registration is widely used as an efficient marketing campaign in Asia. With a pre-registration campaign through social network (e.g., Facebook, Twitter, KakaoTalk, and various game forums, etc.), game publishers allow users to register in advance and provide special rewards in return. The rewards include virtual money, virtual goods (e.g., game items, game avatar, etc.) or privileges to upgrade virtual status. As the pre-registration campaign enables a new game to gain more awareness and thereby reach more consumers, it is an efficient marketing campaign to promote the game. In addition, as the virtual products are only consumed in the new game, it is also an effective way to increase substantial retention of game users.

Previous studies on the online game have mainly focused on understanding the users' motivation for playing multiplayer online games (Hsu and Lu 2007; Park and Jung 2011; Jung et al. 2014; Yee 2005). Another streams of literature based on psychology and sociology explain why players get addicted to playing games or why they pay money for virtual society. For example, Park and Jung (2011) show that the interactivity of the online game community has the biggest impact on users' self-presentation desire. Jung et al. (2014) find that user-centered design 
of MMORPG ${ }^{1}$ influences consumers' perception of product innovation and intention to play. While those studies enlarge our understandings of consumer behavior in the game market, there is only limited research on the economic value of the NPD outcome.

\section{Event Study in the NPD Process}

An event study methodology is widely used in marketing literature to examine the value created from strategic investment decisions such as new product announcements (Austin 1993; Chaney et al. 1991; Markovitch and Steckel 2012; Sood and Tellis 2009; Sorescu et al. 2007; Zantout and Chaganti 1996). Under the efficient market hypothesis (EMH), economically meaningful information in an event is immediately reflected on the stock price after the news release (Fama et al. 1969). Therefore, the abnormal stock returns to new product announcement are good measures to assess market valuation to the new product. Previous literature on the effect of new product introduction on the firm performance (e.g., sales and profits) provides mixed conclusions depending on market situations. By conducting an event study, researchers can estimate the abnormal stock returns to new information and evaluate the net present value of the new product launch. As a game company's pre-registration campaign represents an outcome of a strategic investment decision of the NPD, an event study is considered as the appropriate method to evaluate the market valuation.

\section{Value Relevance of the Pre-Registration Event}

Prior literature on the NPD has documented that new product announcement is related to positive stock returns on average. New products have a great potential to provide new benefits and features that are not offered by existing products. Rubera and Kirca (2012) insist that stock markets acknowledge a firm's innovative efforts and reward them even before the commercialization stage of new products. However, it is not an easy task to predict a new product's success from the initiation stage a priori, because new product project involves risks of failure in nature. Prior studies on innovation have documented the value-relevance of the NPD outcome (e.g., Kelm et al. 1995; Sharma and Lacey 2004). Sharma and Lacey (2004) examine the stock market valuation for the outcome of NPD in the Pharmaceutical industry context. Specifically, they find that the Food and Drug Administration (FDA)'s decisions (approval or rejection) influence the stock market's valuation of the company. Kelm et al. (1995) also suggest that investors react positively to announcements about R\&D projects from the firms with high technological capabilities. For the firms with low technological capabilities, stock investors do not respond until some evidence on the feasibility of new product introduction is revealed.

A typical NPD process consists of several stages including idea generation, idea screening, concept development and testing, business analysis, product development, market testing, and commercialization (Kotler and Keller 2006). In the online game context, pre-registration campaign is generally located between market testing stage and commercialization stage of the NPD process. Suh and Lee (2009) investigate the stock investors' reactions to game companies' announcements on market testing (e.g., public beta tests); however, the abnormal stock returns turn out insignificant. The result in Suh and Lee (2009) suggests that investors perceive that the risk on the new game launch is still high on the market testing stage. Compared to the public beta test, the pre-registration events provide stronger evidence to investors on the completeness of a new game, as the pre-registration comes after completing the market testing stage. Accordingly, the pre-registration event might lead to positive returns whereby reducing the uncertainty about the NPD project completion and signals manager's confidence and optimism about the new product. Thus, we hypothesize that:

$\mathbf{H}_{1}$ : Pre-registration event leads to positive abnormal returns.

\section{Firm Size}

Prior research on the stock market reaction to new product announcement implies that firm size is an important factor that affects returns (Kelm et al. 1995; Rubera and Kirca 2012; Sood and Tellis 2009). Sood and

\footnotetext{
${ }^{1}$ MMORPG (Massively- Multiplayer Online Role Playing Game) is one of the most popular type of online games in which many users participate in role-playing scenarios simultaneously. 
Tellis (2009) show that returns to new product launch are higher for smaller firms than for larger firms. Large firms normally have greater number of financial analysts who evaluate and interpret their financial statement than small firms. Thus, stock investors are less surprised at the new product introduction announcements from large companies. Kelm et al. (1995) suggest that stock investors react more positively on the news from less R\&D intensive firms and small firms, because new product commercialization announcement provides somewhat unanticipated information content. Rubera and Kirca (2012) demonstrate that the firm's innovativeness benefits larger firms more significantly in terms of market and financial position, due to the economies of scale. In contrast, premium for the firm's innovativeness is more likely to put on smaller firms. As prior study suggests higher financial returns to the NPD announcements from smaller firms, we posit that:

$\mathbf{H}_{2}$ : Pre-registration event of small firms yields greater positive abnormal returns than that of larger firms.

\section{EMPIRICAL RESEARCH}

\section{Event Study Analysis} follows.

We measure the stock returns for pre-registration events by estimating normal rate of returns such as

$$
\begin{aligned}
& R_{i t}=\alpha_{i}+\beta_{i} R_{m t}+\varepsilon_{i t} \\
& \hat{R}_{i t}=\hat{\alpha}_{i}+\hat{\beta}_{i} R_{m t},
\end{aligned} \quad t \in\{-260, \ldots,-11\}
$$

where $R_{i t}$ is the rate of stock return for firm $i$ on day $t$, and $R_{m t}$ is the rate of stock return for market portfolio on day $t$. The subscript $t$ indicates the elapsed days from the event, which implies $t=0$ on the event day, and $t=+/-1$, on a day after and before the event date, respectively. In this research, the market portfolio price index is based on "Korea composite stock price index" (KOSPI) and "Korea securities dealers automated quotation" (KOSDAQ) index, for firms enlisted in Korea Stock Exchange (KSE) market and KOSDAQ market, respectively. Using the ordinary least square (OLS) estimates in Equation 1, we obtain normal rate of return, $\hat{R}_{i t}$, and regard the difference between the actual rate of return and the normal rate of return $\left(R_{i t}-\hat{R}_{i t}\right)$ as the abnormal rate of return, $A R_{i t}$. To obtain estimates needed to calculate the $A R_{i t}$, we utilize 250 stock price observations prior to 10 business days before the events.

In our research, we set the event window a period of 11 consecutive business days centered on the event date $(t \in\{-5, \ldots,+5\})$. We examine the existence of abnormal return by calculating average abnormal returns (AAR) and T-statistics (T_AAR) such as following;

$$
\begin{aligned}
& A A R_{t}=\sum_{i=1}^{I} \frac{A R_{i t}}{I} \\
& T_{-} A A R_{t}=\sum_{i=1}^{I} \frac{A R_{i t} / \hat{\sigma}_{i}}{\sqrt{I}}, \quad \text { for } t \in\{-5, \ldots,+5\}
\end{aligned}
$$

where $I$ is the number of observations, and $\hat{\sigma}_{i}$ is the standard deviation of $A R_{i t}$. Additionally, we calculate cumulative average abnormal returns (CAAR) to track the cumulative effects starting from the earliest day of the event window $(t=-5)$ to the specified day $(t=\tau)$, by the following equation.

$$
C A A R_{t}=\sum_{\tau=-5}^{t} A A R_{\tau}, \text { for } t \in\{-5, \ldots,+5\}
$$

\section{Data Description - Korean Game Companies}

For our event study, we derive events by searching news articles related to pre-registration of new game launch performed by Korean firms, from a search engine in Korea. We collected 153 event observations from 19 Korean game companies enlisted in Korea Stock Market in our research period, from 2010 to 2014. In order to measure the abnormal return rigorously, we exclude observations such as followings. First, we exclude observations 
from our research if the company's available stock price data does not match our specified estimation period $(t \in\{-260, \ldots,-11\})$, to secure the same estimation period across various events. Second, we exclude observations if the beta estimates from the estimation period $(t \in\{-260, \ldots,-11\})$ are insignificant, as we cannot measure the normal return by the linearity assumption between normal return and market return. Lastly, we also exclude observations when major events other than pre-registration happen during the specified event window $(t \in$ $\{-5, \ldots,+5\})$, to clarify that our observation is mainly affected by pre-registration. Table 1 shows the asset and market value for the firms investigated in our research. According to Table 1, the maximum amounts of asset and market value of the firms are 78 and 192 times greater than the minimum amounts, respectively, which shows great variability of the firm size.

Table 1. Asset and Market Value for Firms (Unit: billion KRW)

\begin{tabular}{c|c|c}
\hline & Asset & Market Value \\
\hline Mean & 497 & 647 \\
Median & 171 & 375 \\
S.D. & 647 & 732 \\
Min & 26 & 34 \\
Max & 2,035 & 6,546 \\
\hline
\end{tabular}

Notes: 1. Number of observations is 153.

2. Asset and Market Value are as of the end of prior quarter of each event.

3. As of Feb, 2015, 1 billion KRW is approximately 0.9 million USD.

\section{Empirical Findings of the Event Study}

Table 2 shows average abnormal returns (AAR), T-statistics (T_AAR), and cumulative average abnormal returns (CAAR). In Table 2, $T_{-} A A R_{1}$ is significantly positive, which supports Hypothesis 1 . The signs of $A A R_{t}$ change until the event day $(t \in\{-5, \ldots, 0\})$ but remain positive after the event day $(t \in\{1, \ldots, 5\})$, showing insignificant t-statistics for all but $t=1$. The event affects significantly only on a day after the event date $(t=1)$, neither event date $(t=0)$ nor any other days. We can infer from these results that stock investors tend to wait and see the real market reaction of the pre-registration event for at least a day, rather than instantly react to the event itself. A day might be enough for the interested stock investors to evaluate the incremental future cash flows from the new game launch of the company, from various sources such as news articles, social network services (SNS), communities, forums, etc. In this way, the expectation of incremental future cash flows from new game is significantly reflected on the abnormal return on the stock price of the company on a day after the event $(t=1)$.

Table 2. Average Abnormal Returns (AAR), T-Statistics (T AAR), and Cumulative Average Abnormal Returns (CAAR)

\begin{tabular}{c|r|r|r}
\hline $\boldsymbol{t}$ & AAR & T_AAR & CAAR \\
\hline-5 & -0.0002 & -0.072 & -0.0002 \\
-4 & 0.0009 & 0.355 & 0.0007 \\
-3 & -0.0002 & -0.064 & 0.0005 \\
-2 & -0.0030 & -0.982 & -0.0026 \\
-1 & 0.0016 & 0.624 & -0.0010 \\
1 & -0.0010 & -0.344 & -0.0020 \\
2 & 0.0066 & $2.470 *$ & 0.0046 \\
3 & 0.0002 & 0.059 & 0.0048 \\
4 & 0.0029 & 1.073 & 0.0077 \\
5 & 0.0042 & 1.159 & 0.0119 \\
\hline
\end{tabular}

Note: *- significant at the $5 \%$ level.

We depict the histogram of $A R(t=1)$ in Figure 1, in order to see the distribution of $A R$ among the events, especially on the day when $A A R$ value is significantly different from zero $(t=1)$. The shape of distribution demonstrates wide range of the abnormal rate of returns from -0.08 to 0.13 , which shows wide spectrum of stock investors' market valuation related to the event, covering widely both negative and positive sides. We also find that the distribution of abnormal return takes a bimodal shape, the 1 st modal point at 0.02 and the 2 nd modal point at 0.01 , which implies that evaluation in either way, positive or negative, is more frequent than neutral evaluation 
about the new game launch. In addition, the long-tail skewed to the right (0.971) implies that investors have strongly positive expectations for new game launches of some companies.

Figure 1. Histogram of Abnormal Returns on a day after the event day $(t=1)$

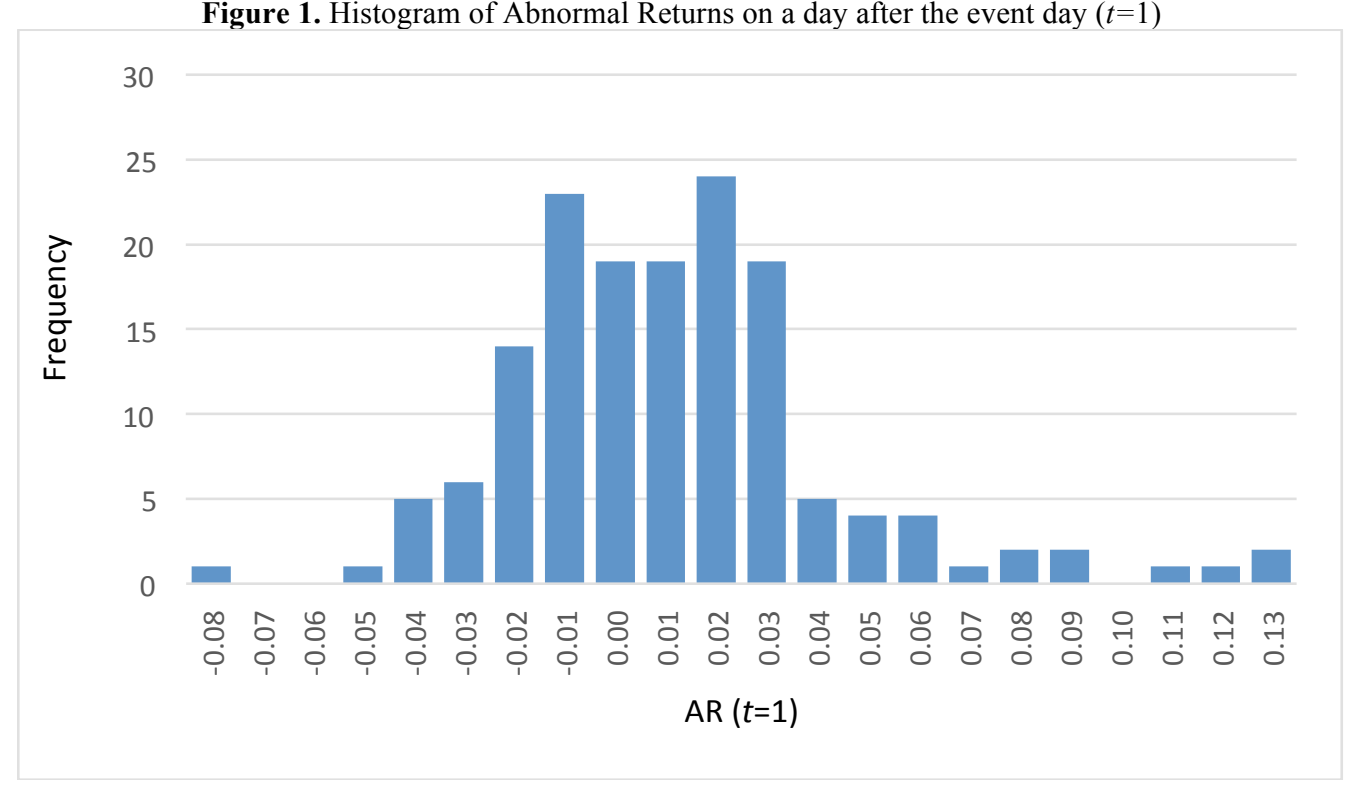

In Table 2, CAAR $R_{t}$ within the event window is always positive and continuously increasing after the event $(t \in\{1, \ldots, 5\})$. This implies that cumulative average market value of firms increase during the event window. Figure 2 depicts the dramatic increase of $C A A R_{t}$ after the event days $(t \in\{1, \ldots, 5\})$, in contrast to the fluctuating states until the event $(t \in\{-5, \ldots, 0\})$. Based on the cumulative average abnormal return at the end of event window, $C A A R_{5}$, we can infer the market value of firms, triggered by the pre-registration event information, increase by $1.49 \%$. If we assume the given event window period reflects all the impacts of pre-registration information on the market value of firms, the $1.49 \%$ increase implies approximately 9 million USD increase of average market value of firms. $^{2}$

\footnotetext{
${ }^{2}$ Following Table 1, this figure is based on the mean value of market value of firms (647 billion KRW). If we use median value ( 375 billion $\mathrm{KRW}$ ) instead, the $1.49 \%$ increase implies 5 million USD.
} 
Figure 2. Trend of Cumulative Average Abnormal Returns $\left(C A A R_{t}\right)$

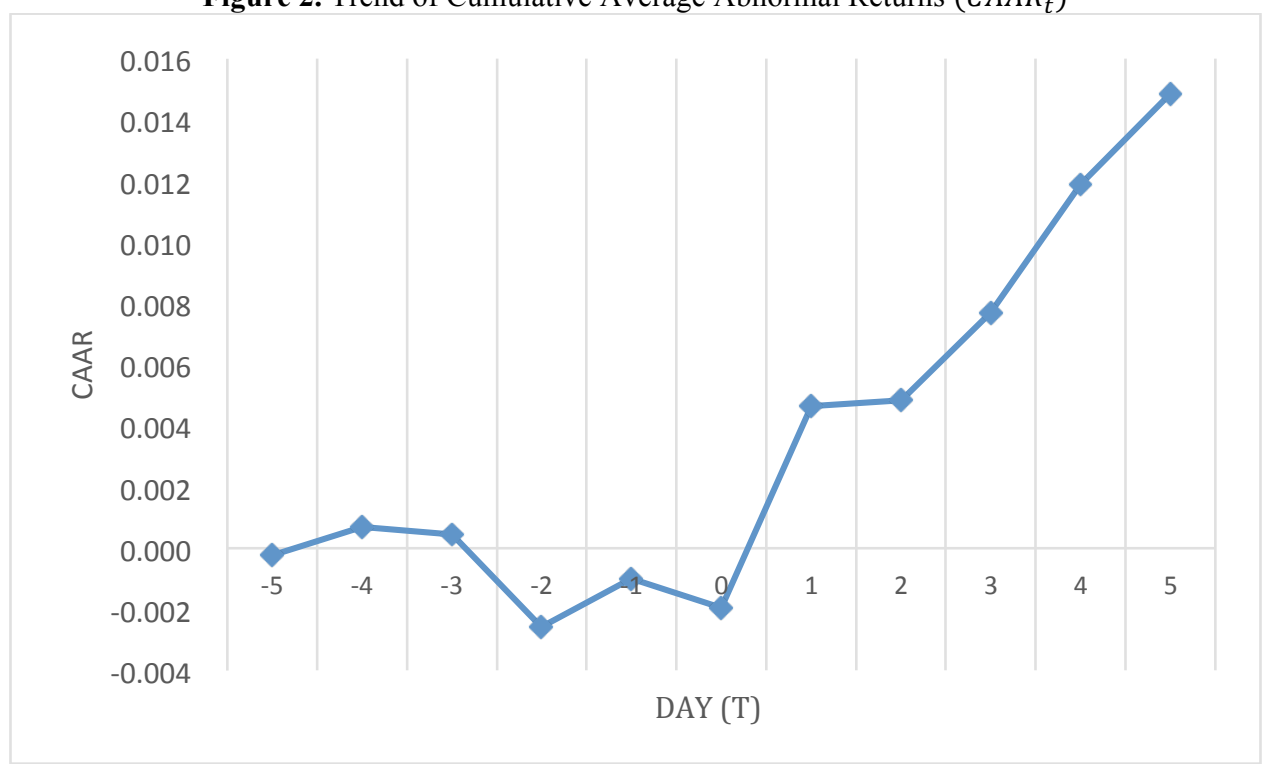

\section{The Impact of Firm Size on the Abnormal Return}

As an additional step of our event study analysis, we examine the impact of firm size on the abnormal return. Specifically, we regress the abnormal returns of a day after the event on firm size. Consistent with Picou and Rubach (2006), we use the logarithm of total asset as a size measure.

$$
A R_{i}=\gamma+\delta \cdot \text { LnAsset }_{i}+\varepsilon_{i}
$$

where $\operatorname{LnAsset}_{i}$ is the $\log$ of asset of the company $i$, and $\gamma, \delta$ are the related parameters.

In Table 3 , both of the intercept coefficients, $\gamma$, and the coefficients for size variables, $\delta$, are significantly different from zero. As the $\delta$ estimate is significantly negative, our hypothesis 2 is supported. Figure 3 is the scatter plot of firm size $\left(\right.$ LnAsset $\left._{i}\right)$ and the abnormal return on a day after the event, showing also the negative trend line.

Table 3. The Influence of Firm Size on the Abnormal Return on a Day after the Event Day $(t=1)$

\begin{tabular}{c|c|c}
\hline Coefficient & $\boldsymbol{\gamma}$ & $\boldsymbol{\delta}$ \\
\hline Mean (s.d.) & $0.092^{*}(0.051)$ & $-0.003^{*}(0.002)$ \\
t-value & 1.790 & -1.664 \\
p-value & 0.076 & 0.098 \\
\hline
\end{tabular}

Note: *- significant at the $10 \%$ level. 
Figure 3. The Scatter plot of Firm Size and the Abnormal Return on a Day after the Event Day $(t=1)$

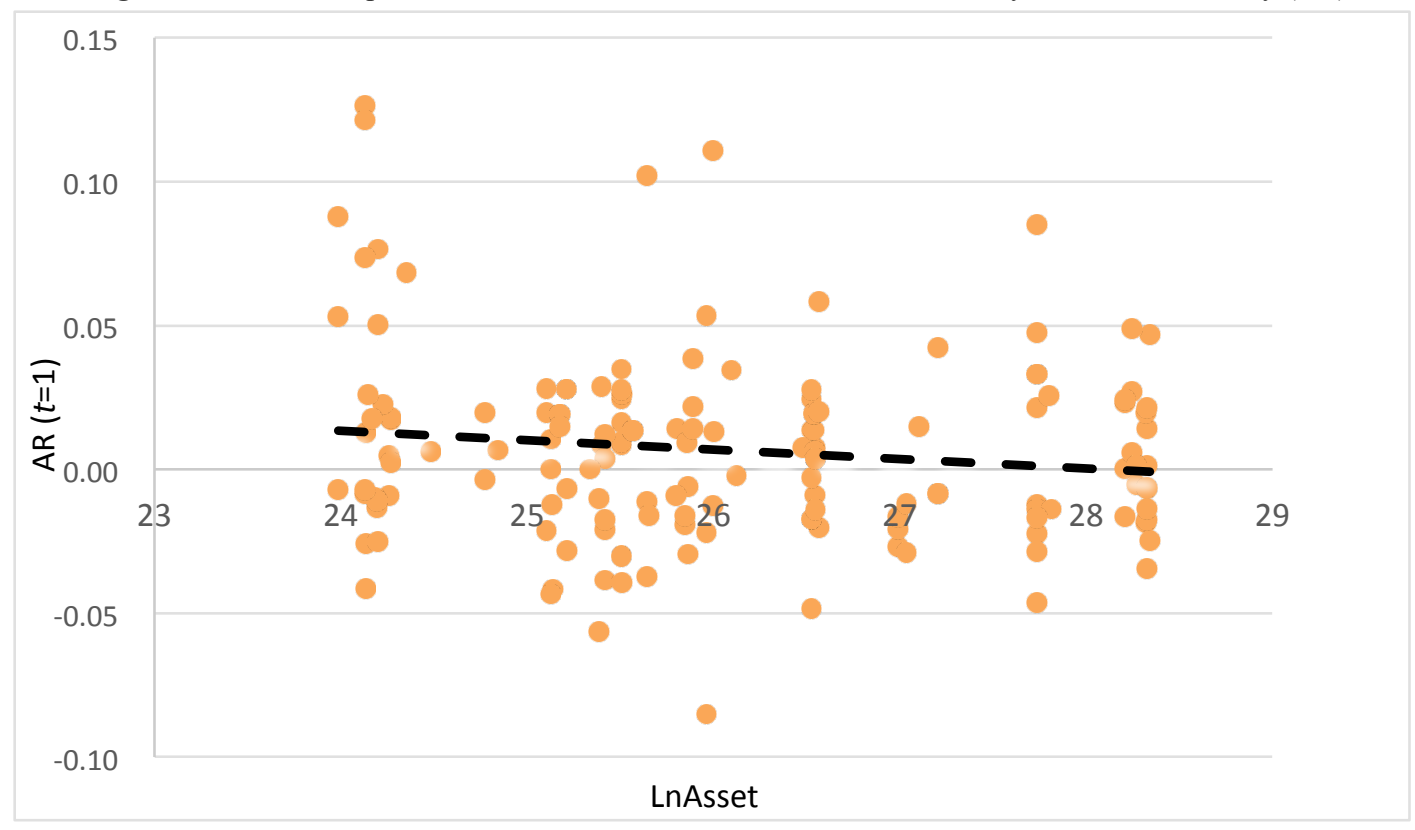

This result suggests that stock market investors who are exposed to the information of pre-registration expect small firms higher returns from new game launch, which is consistent with Sood and Tellis (2009). As new product launch information is more unanticipated information for small firms, rather than large firms (Kelm et al. 1995), the effect of pre-registration information from small firms on investors' evaluation for innovativeness is greater. Therefore, small-sized firm considering new game launch need not worry about being undervalued in the stock market just because of its size. Rather, our result suggests that new game launch is a good opportunity especially for small firms to send positive signals to stock investors in terms of their innovativeness, as well as to improve their market values.

\section{CONCLUSION}

This research aims to examine the economic value of the pre-registration marketing campaign in the online game as an outcome of the NPD process. In an effort to empirically test whether the abnormal stock return related to the event exists, we performed the event study analysis on the market valuation of innovative outcome. This study not only elucidates the economic value of the pre-registration marketing campaign, but also provides new insights on the financial value of the NPD process in the game industry. In addition, this research also verifies whether the firm size affects the stock market reactions related to the pre-registration event.

Our major empirical findings indicate that stock investors expect that the pre-registration event of new game launch would affect future cash flow of the firm positively. The pre-registration event generates significantly positive abnormal returns on a day after the event day. This result also demonstrates that the event of pre-registration has valuable economic information for stock investors. Therefore, we suggest managers to consider the instant impacts of the pre-registration on the stock market, as well as the long term cash flows from the new game. Another empirical finding is the existence of the influence of the firm size on the abnormal return, higher abnormal returns for small firms. This analysis implies that investors' expectation about the impact of pre-registration on the stock price depends on the size of the company. Also, this result suggests that small firms might send positive signals to stock investors about their innovativeness, by the pre-registration marketing campaign.

This research has also several limitations. In order to overcome these limitations, we discuss possible future research directions as well. First, our empirical analysis might lead to different results in different stock markets, where the characteristics of stock investors and companies are different from Korea. To generalize our empirical results, a cross validation approach would be a good direction of future research. Second, due to the limited access to information, we do not measure the performance of pre-registration such as the number of pre-registers, which 
can be meaningful information for stock investors and managers. If an additional source of information is accessible, a research for optimal pre-registration promotion considering market value of the firm would be also a possible extension of this research. As Gruca and Rego (2005) indicate, this stream of research not only strengthens the marketing-finance interface, but also contributes to marketing's voice at general management decisions.

\section{ACKNOWLEDGMENTS}

We have benefitted from assistance of Jiseung Ha.

\section{AUTHOR INFORMATION}

Jihong Min is an assistant professor at College of Business Administration of Myongji University, South Korea. He earned his Ph.D. at Purdue University. His research areas include structural consumer model, database marketing, and marketing-finance interface. E-mail: jhmin@mju.ac.kr (first author)

Yun Kyung Oh is an assistant professor at Department of Business Administration of Dongduk Women's University, South Korea. She received her Ph.D. at Purdue University. Her research interests include digital marketing, online retailing and financial value of marketing investment. E-mail: ykoh1@dongduk.ac.kr (corresponding author)

\section{REFERENCES}

Austin, D. H. (1993). An event-study approach to measuring innovative output: The case of biotechnology. The American Economic Review, 253-258.

Chaney, P. K., Devinney, T. M., \& Winer, R. S. (1991). The impact of new product introductions on the market value of firms. Journal of Business, 573-610.

Cooper, R. G. (2005). New products-what separates the winners from the losers and what drives success. The PDMA Handbook of New Product Development, Second Edition, 3-28.

Fama, E. F., Fisher, L., Jensen, M. C., \& Roll, R. (1969). The adjustment of stock prices to new information. International Economic Review, 10(1), 1-21.

Fang, E., Lee, J., \& Yang, Z. (2015). The Timing of codevelopment alliances in new product development processes: returns for upstream and downstream partners. Journal of Marketing, 79(1), 64-82.

Gaudiosi, J. (2012). New Reports Forecast Global Video Game Industry Will Reach $\$ 82$ Billion By 2017, Forbes, July. 19, Accessed at Jan, 28, 2015.

[Available at http://www.forbes.com/sites/johngaudiosi/2012/07/18/new-reports-forecasts-global-video-gameindustry-will-reach-82-billion-by-2017]

Gruca, T. S., \& Rego, L. L. (2005). Customer satisfaction, cash flow, and shareholder value. Journal of Marketing, 69(3), 1-130.

Hsu, C. L., \& Lu, H. P. (2007). Consumer behavior in online game communities: A motivational factor perspective. Computers in Human Behavior, 23(3), 1642-1659.

Jung, H. S., Kim, K. H., \& Lee, C. H. (2014). Influences of perceived product innovation upon usage behavior for MMORPG: Product capability, technology capability, and user centered design. Journal of Business Research, 67(10), 2171-2178.

Kelm, K. M., Narayanan, V. K., \& Pinches, G. E. (1995). Shareholder value creation during R\&D innovation and commercialization stages. Academy of Management Journal, 38(3), 770-786.

Kim, S. K. (2014). Com2uS: Mobile game pioneer. International Journal of Teaching and Case Studies, 5(2), 189196.

Kotler, P. and Keller, K. L. (2006). Marketing Management, 12th edition. Upper Saddle River, NJ: Pearson Education.

Markovitch, D. G., \& Steckel, J. H. (2012). Do initial stock price reactions provide a good measurement stick for marketing strategies? The case of new product introductions in the US. European Journal of Marketing, 46(3/4), 406-421.

Moreira, Á. V., Vicente Filho, V., Barros, G. A., de Carvalho, L. V., \& Albuquerque, G. L. R. (2013). Which features matter to make a successful mobile game? SBC-Proceedings of SBGames 2013.

Copyright by author(s); CC-BY 
Oh, Y.K., \& Min, J. (2015). The mediating role of popularity rank on the relationship between advertising and inapp purchase sales in mobile application market. Journal of Applied Business Research, Forthcoming.

Park, S. B., \& Chung, N. (2011). Mediating roles of self-presentation desire in online game community commitment and trust behavior of Massive Multiplayer Online Role-Playing Games. Computers in Human Behavior, 27(6), 2372-2379.

Pearson, D. (2014). Report: Mobile to become gaming's biggest market by 2015, Gameindustry.biz, Oct. 22, Accessed at Jan, 30, 2015.

[Available at http://www.gamesindustry.biz/articles/2014-10-22-report-mobile-to-become-gamings-biggest-marketby-2015]

Picou, A., \& Rubach, M. J. (2006). Does good governance matter to institutional investors? Evidence from the enactment of corporate governance guidelines. Journal of Business Ethics, 65(1), 55-67.

Rubera, G., \& Kirca, A. H. (2012). Firm innovativeness and its performance outcomes: A meta-analytic review and theoretical integration. Journal of Marketing, 76(3), 130-147.

Sharma, A., \& Lacey, N. (2004). Linking product development outcomes to market valuation of the firm: The case of the US pharmaceutical industry*. Journal of Product Innovation Management, 21(5), 297-308.

Sood, A., \& Tellis, G. J. (2009). Do innovations really pay off? Total stock market returns to innovation. Marketing Science, 28(3), 442-456.

Sorescu, A., Shankar, V., \& Kushwaha, T. (2007). New product preannouncements and shareholder value: don't make promises you can't keep. Journal of Marketing Research, 44(3), 468-489.

Srinivasan, S., Pauwels, K., Silva-Risso, J., \& Hanssens, D. M. (2009). Product innovations, advertising, and stock returns. Journal of Marketing, 73(1), 24-43.

Srivastava, R. K., Shervani, T. A., \& Fahey, L. (1998). Market-based assets and shareholder value: A framework for analysis. Journal of Marketing, 2-18.

Suh, C. W, \& Lee, B. L. (2009). An analysis on events in online games and stock price reactions. Proceedings of The Korea Society of Management Information Systems, 482-489.

Yee, N. (2006). Motivations for play in online games. Cyber Psychology \& Behavior, 9(6), 772-775.

Zantout, Z., \& Chaganti, R. (1996). New product introductions, shareholders' wealth, and first-mover advantages. Journal of Financial and Strategic Decisions, 9(3), 49-61. 